\title{
The Challenges and Opportunities for Chinese Overseas Postgraduates in English Speaking Universities
}

\author{
$\mathrm{Xu} \mathrm{Liu}{ }^{1,2}$ \\ ${ }^{1}$ Sichuan Normal Univetsity, Chengdu, China \\ ${ }^{2}$ Institute of Education, University College London, London, United Kingdom \\ Correspondence: Xu Liu, Institute of Education, University College London, London, United Kingdom. E-mail: \\ liuxubright@gmail.com
}

Received: January 29, 2015

Accepted: March 30, 2015

Online Published: May 25, 2015

doi:10.5539/hes.v5n3p45

URL: http://dx.doi.org/10.5539/hes.v5n3p45

\begin{abstract}
An increasing number of Chinese students pursue their higher education degree in an overseas university. This research paper sets out to raise a discussion about some of the major challenges that such Chinese postgraduates might experience when studying at universities in English speaking countries drawing from ethnographic and sociological perspectives. The paper seeks to enhance understanding of a growing phenomenon amongst student communities in Higher Education institutions in English speaking countries. The challenges faced by Chinese students can be disorientating and stressful but overcoming them can lead to opening up of a range of opportunities from which the students can benefit particularly after they have graduated from their study. As many HE institutions come to depend upon the growing number of Chinese students enrolling with them the paper touches upon an issue of cross national concern. Both authors have experience of students seeking to study in English-speaking countries. They are currently pursuing research at the Institute of Education, University College London. The present paper is drawn from a wider programme of research into student exchanges and flows.
\end{abstract}

Keywords: challenges, opportunities, Chinese, overseas postgraduates

\section{Introduction and Background}

This paper would like to begin this paper by referring to a study which exerted considerable influence over many years upon the study of students abroad and which risks being forgotten in the deluge of new work appearing on this theme. Oberg (1960) (Note 1) argued long ago, for there being four stages of cultural adjustment for students studying abroad. His four stages were the honeymoon followed by regression, leading to adjustment and concluding with recovery.

Oberg suggested that for students who are at the honeymoon stage, anything new is intriguing and exciting, new-comers tended to be impressed as they arrived into the worlds of their new university settings. Gradually, the focus of the new-comer turned from the new and exciting to the basic, everyday factors which will seemed to appear from every corner and could be troubling for the individual. For Oberg this became the regression stage when being away from home could feel disorientating and upsetting. In the third stage, students adjusted, having survived their crisis, and they began their journey of recovery. In this final stage, recovery could result in an ability to function in both the adopted setting and culture while also for many, re-asserting the values and practices that they were accustomed to and a new inter-cultural confidence began to appear. Although Oberg's schema quite obviously would not fit every student's experience, his thinking nevertheless provides us with an interesting starting point for the discussion that follows.

One aspect of recent globalization in the educational field has been that an increasing number of students opt to go to foreign countries to pursue their postgraduate Degrees, despite knowing in advance of the likely challenges they will have to face and overcome. Within worldwide figures the largest national groups of foreign students studying outside of their home country come from China, India and Korea (Organisation for Economic Co-operation and Development [OECD], 2013). Therefore although the present paper has a Chinese focus, what is said could apply to a range of national groups. Japan has slipped down the league table and in part this may reflect the economic stagnation that has been affecting that country for at least the past decade. The country 
which attracts the fastest growing percentages of students of Asian national origin is the UK, where transfer earnings into the Higher Education sector of the economy have become a key element within the balance of trade figures. For the UK and a few other countries, Higher Education is big business (OECD, 2013). As can be seen from Figure 1 below, for the past decade, numbers of Chinese post-graduate students pursuing Higher Education overseas has been increasing at a rate approaching 20\% each year (Report from Chinese Central TV, 2013).

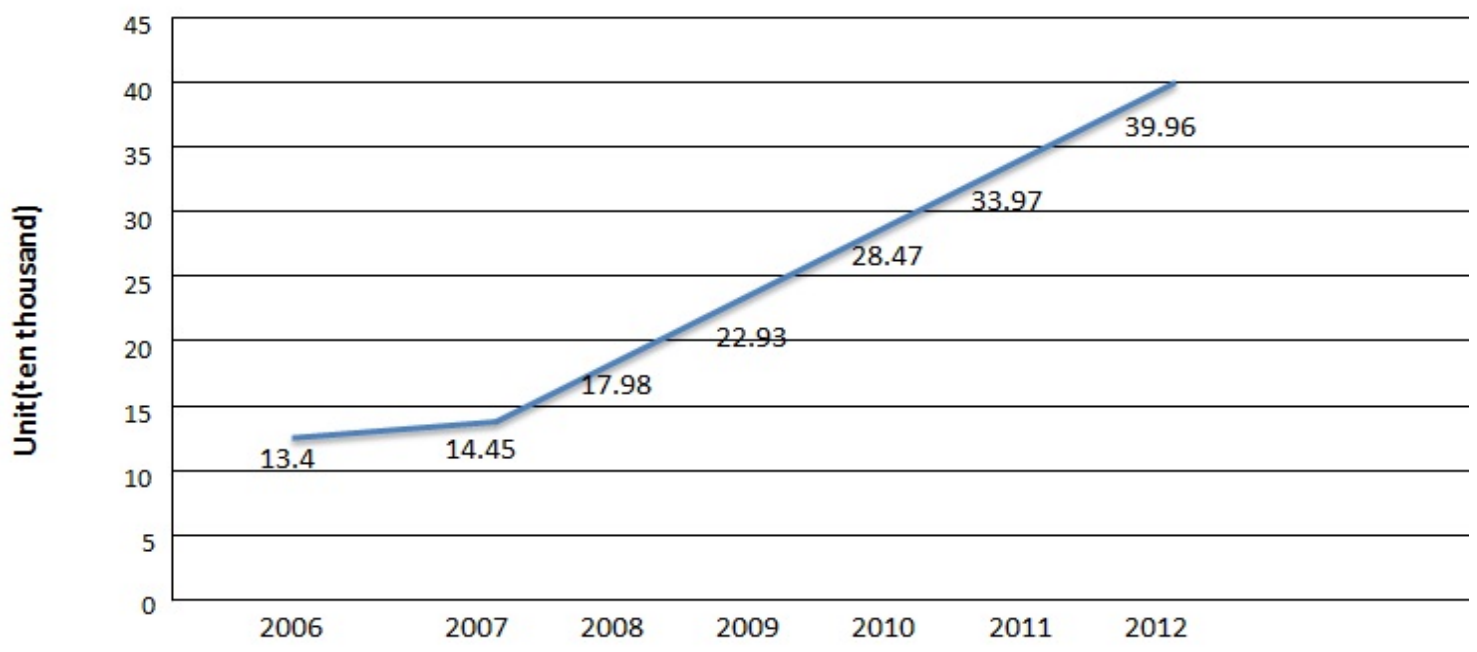

Figure 1. Chinese students studying abroad between the Years 2006-2012 (Note 2)

The gross number of Chinese students studying abroad was 2,644,700 between the 34 years spanning 1978 and 2012 (China Education Online, 2013). Figure 1 above indicates that the annual increases in percentage terms of Chinese students who study in abroad has expanded continuously by over $20 \%$ from 2007 to 2011 . This figure reached almost 400,000 Chinese students studying abroad in 2012 and more recent estimates suggest that a mere two years later (2014) the figure has risen to nearer 450,000. The annual percentage rise for 2012 was $17.65 \%$ meaning that total annual growth in numbers amounted to less than 60,000 , a slowing down of the rate of increase upon previous years.

Despite this levelling of the rate of growth, the trend continues in an upward direction with a likelihood of the figure reaching 500,000 by 2015 . Such astonishing figures reveal a number of things. Firstly that the opening up of Chinese young adults who have been successful at Masters Level to further foreign study, will lead to a generation of academics and intellectuals part of whose training and education will not be Chinese. Secondly, such numbers mean that the economies of many high-ranking universities in English speaking countries, now significantly rely upon income from Chinese student registration. This means that China as a growing cultural power in the world has purchasing influence, something that has been seen in relation to the recent relaxation of visa arrangements in both Australia and the UK. One example of such symbiotic relations between university and a key segment of students is the case of Imperial College, London one of the world's top-ranking scientific universities where around 1500 Chinese students were registered in the 2013/2014 academic year according to university information (Note 3).

\subsection{The History of Chinese Students Travelling English Speaking Countries for Higher Education}

There is a long history to Chinese students travelling abroad for Higher Education in English speaking countries, beginning with Rong Hong, who went to America to study in 1847 and then returned to China in 1854 after graduating from Yale University (Yao, 2004). Yao has shown how the first surge of Chinese studying abroad occurred during the early 20th century, something that was interrupted by the Sino-Japanese war of 1936 . Initially this was not such a problem as many of the first Chinese students studying abroad originated from the New Territories and Hong Kong where English had become widely understood and spoken. Similarly many early Chinese students to the USA and UK came from Guangdong where strong business and trading links had created a wide familiarity with use of English. In the immediate period of the People's Republic of China inaugurated in 1949, some students were sent to study abroad. In accordance with the policy of studying in the Soviet Union and eastern European socialist countries of "Orientation, Focus and Abundance" (Cheng \& Miao, 
2010) large numbers of students were sent to just a few countries limited to the socialist bloc countries or to Chinese-friendly developing countries before the period of Chinese economic reforms (Yao, 2004) from 1978 onwards. There are more than 200 provincial level leaders, more than 100 generals and more than 200 academicians of the academy of sciences and the academy of engineering among this cohort of students who studied in these socialist countries (Li \& Dong, 2005).

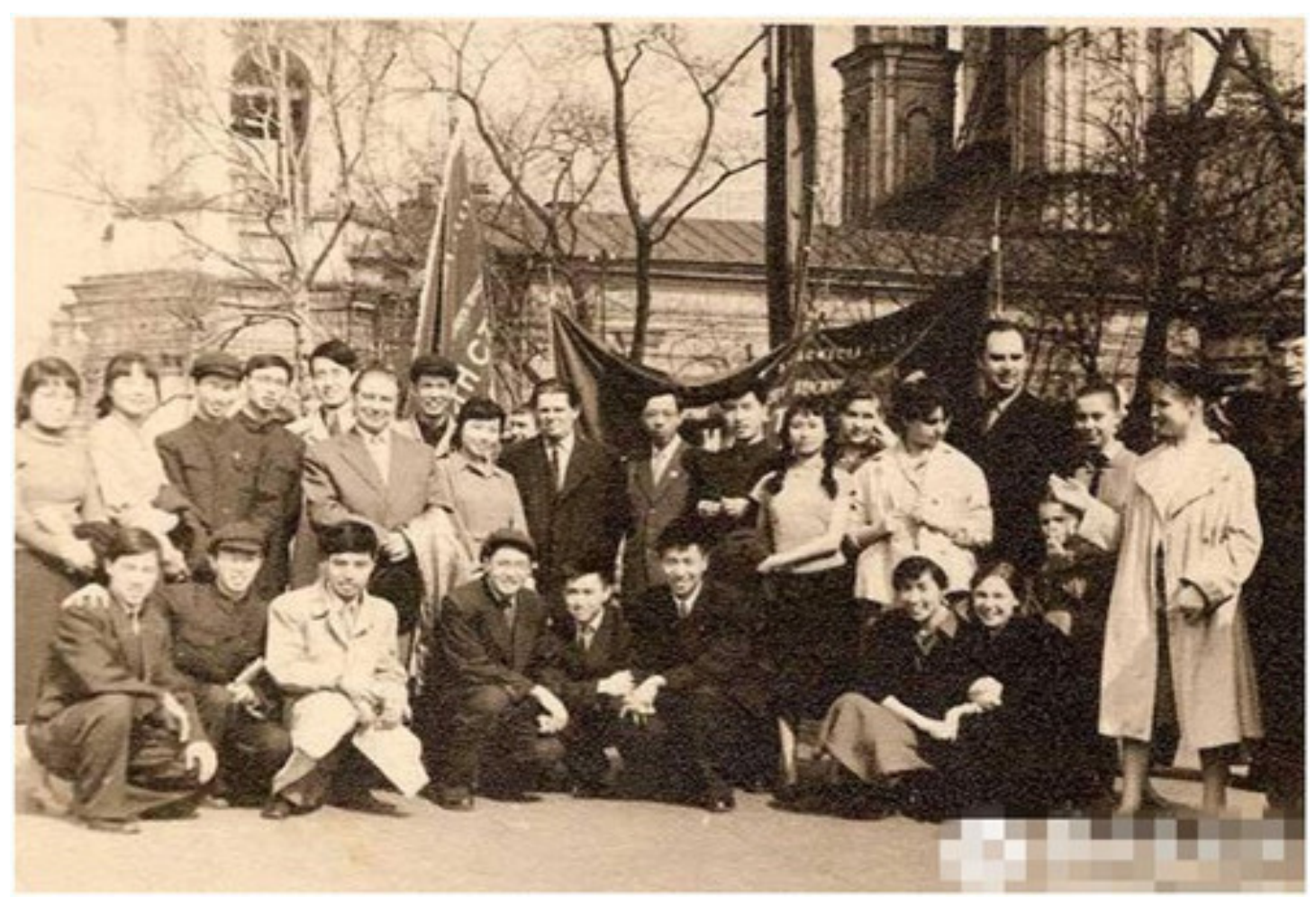

Figure 2. Chinese students in Moscow during the 1950s (Note 4)

The flow of students in the post-War period was in the direction of north east into the Soviet Union, travelling as far as Moscow. Russian was the lingua franca of those times within China for those intending to study abroad. Personal challenges experienced by students going abroad, were to some extent reduced for individuals because most went on scholarships and there were strong ideological connections between the two socialist countries. The image above shows us that some students adopted typically revolutionary attire whereas others adapted to fashionable "western" styles. So Oberg's stages of transition may not have been experienced in quite the same way in the post-1949 period.

\subsection{A Surge of Students Heading to English Speaking Country after the Deng Xiaoping Reforms and Opening-Up}

Following the Deng Xiaoping reforms and opening-up of the economy, an increasing number of Chinese families were able to afford the tuition fees for their children to study abroad. Consequently, there appeared a new surge of students heading to destinations like the USA, Australia, Canada and the UK. This was also supported by an increase in government scholarships to universities in English speaking countries. The changing characteristics of the student cohorts is revealed by recent figures from Wang Huiyu and Li Nan (2008) who point out that in the period between 1978 and 1992 the total number of state scholarships for studying abroad amounted to 94,170; In 2007, there are 12,402 state scholarship holders which increased 46\% from 8,242 of the year of 2006. Wang Huiyu points out within these state scholarship holders, over half already held a Chinese $\mathrm{PhD}$ degree before studying at overseas universities and currently $78 \%$ of vice-chancellors of universities governed by the Ministry of Education have study experience overseas. In 2007, the State Construction High-level University Overseas $\mathrm{PhD}$ programme was initiated by the Chinese government which sought to increase numbers returning from world-ranking overseas universities to take up positions in Chinese universities. 
Through this programme, 5,000 carefully selected students were sponsored annually between 2007-2011 to pursue $\mathrm{PhD}$ degrees at world ranking universities. In 2008, 6,000 students were sponsored through this programme, and 2014 this number has risen to 7,000. The figures reveal a clear policy intention of the education authorities in China to upgrade the quality and qualifications of future senior leaders within the HE sector.

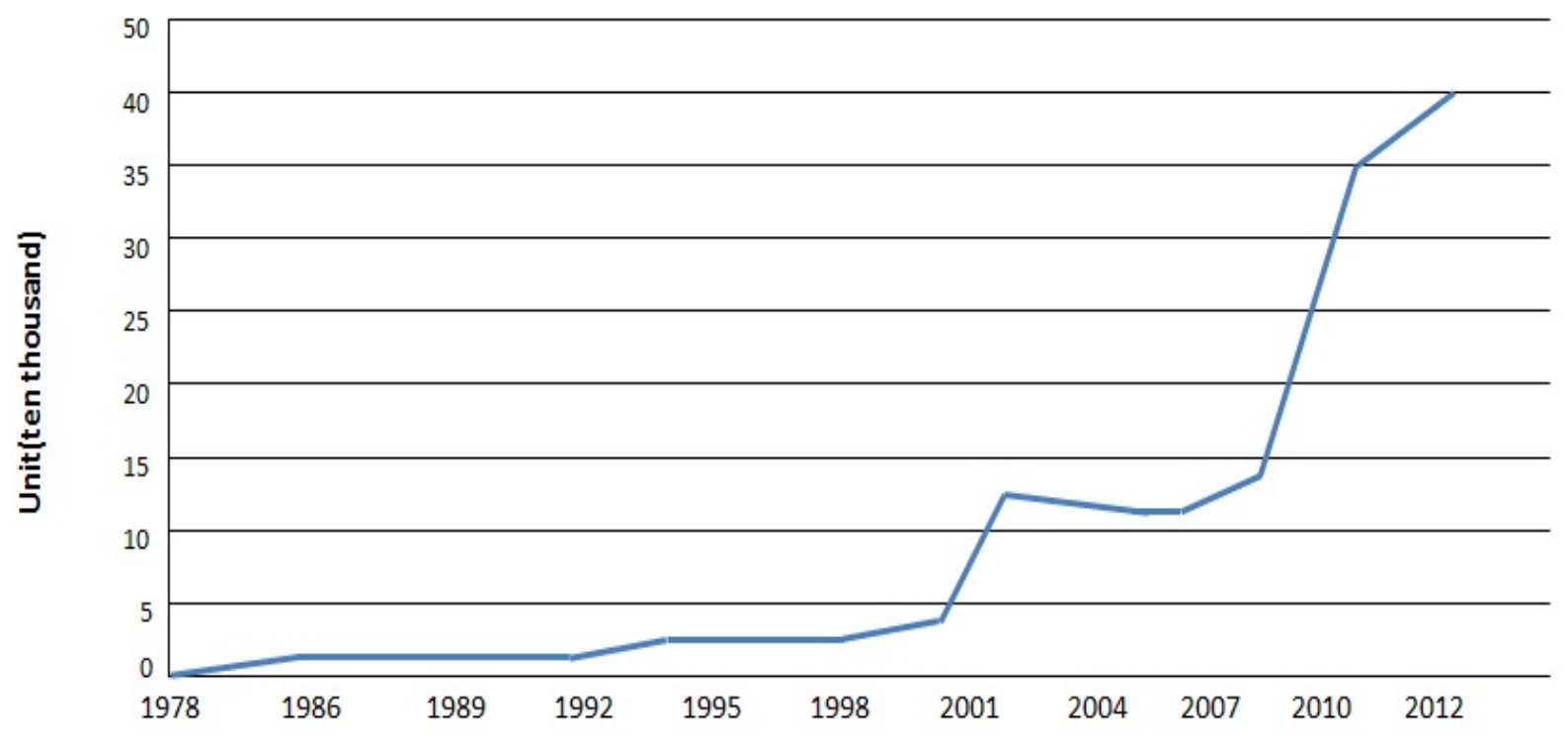

Figure 3. Chinese overseas students (Note 5)

Figure 3 shows that Chinese overseas student numbers totalled about 700,000 between 1978 and 2003. Within these years, student numbers greatly increased after 2000 and then began rapid expansions from 2000 to 2002 and from 2006 to 2011 with the annual increases of up to $20 \%$. It is therefore clear that in the first years of the 21 st century there was a structural shift within the society as tens of thousands of self-funded students sought to enhance their educational and cultural capital by acquiring a post-graduate Degree from a world-ranking English-speaking university. Another way of expressing this is that the parents of these young people sought to enhance their children's cultural and academic capital by paying for them to study abroad. The ability of parents to pay for such university fees arises in part from the structural shifts within family life arising from the one-child policy. This has led to married couples who have been continuously employed and salaried and who have also achieved a number of career promotions, to have substantial disposable surplus income by the time their child reached the age of 18. Such socio-economic shifts arising from economic growth and stability have combined with traditional Chinese attitudes towards education expressed as:

万般皆下品 The worth of other pursuits is small

唯有读书高 The study of books excels them all (Note 6)

At the same time, in 2001, the Ministry of Personnel promulgated the policy of Encouraging Measures about Chinese High-level Overseas Talents to come back to China to work, arguing that as the State offered funding, the citizen should have a responsibility to return and make a social contribution. In 2003, the government established the Self-funding Students Overseas Scholarship scheme. These policies clearly reflect the supportive attitude of the government to students studying overseas. The figure cited above in Figure 3. Therefore, need also to be understood as reflecting purposeful policy emanating from the Chinese government.

\subsection{The Extent of Recent Changes in Chinese Overseas Student Flows}

The extent of recent changes in student flows can be further illustrated using OECD figures examining national market shares of international students in Higher Education. Figure 4 is an adaptation by the author from OECD research and now includes statistics relating to China. 


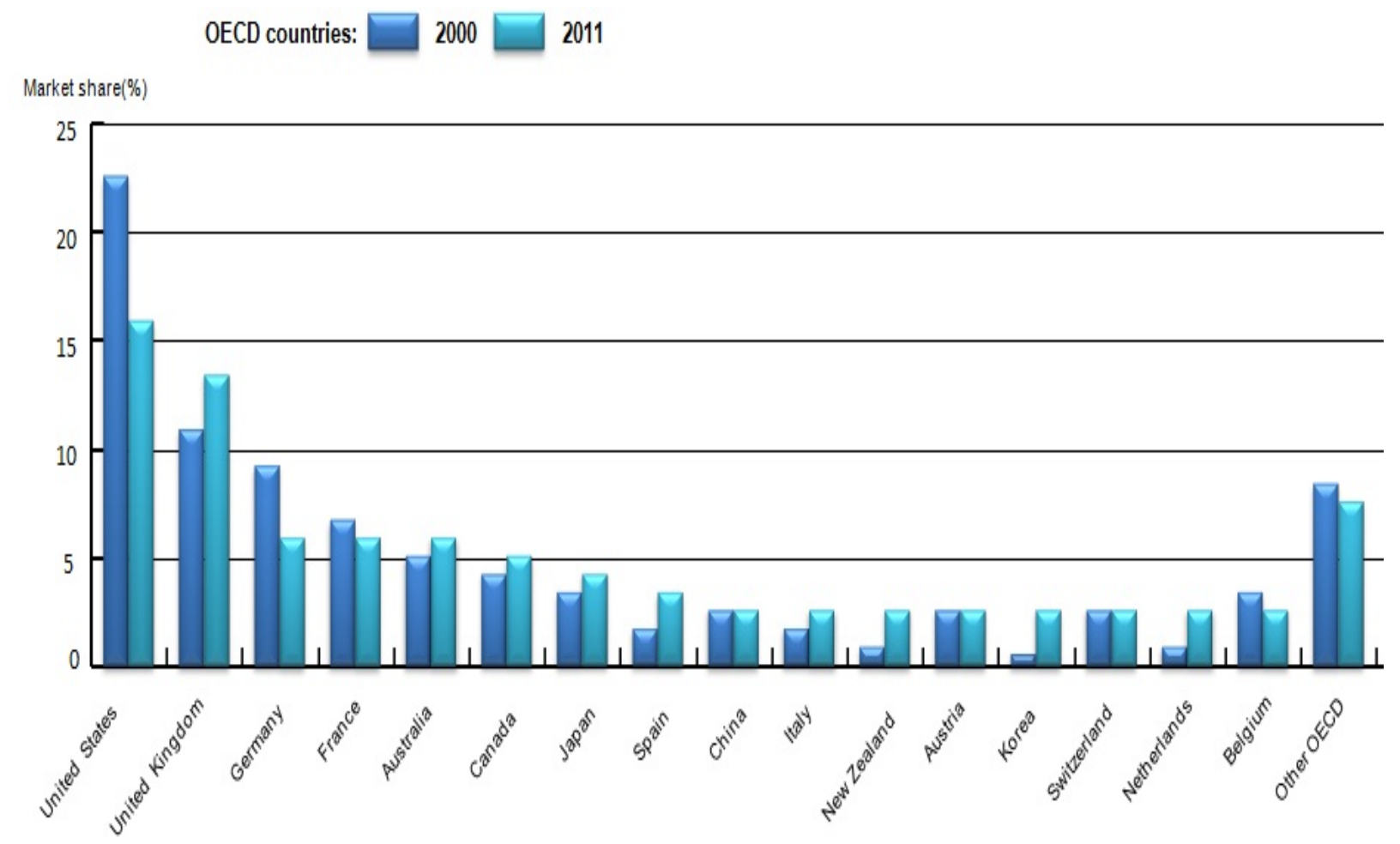

Figure 4. Trends in international H.E. market shares $(2000,2011)$ (Note 7$)$

As shown above, the United States and United Kingdom account for the largest market share of $34 \%$ in 2000 and $30 \%$ in 2011 respectively. Following these two countries, are Germany, France, Australia and Canada combined, accounting for a further $21 \%$ of the global market shares in both 2000 and 2011 . Interestingly, while the percentage of the United States and Germany decreased in 2011, the percentage of the United Kingdom increased. The figures permit the inference that the UK has been taking over a percentage of the business lost by United States and Germany. In the United States, the growth in numbers of international students is now significantly driven by students coming from China. The enrollment of Chinese student increased by 21 percent in total to almost 235,000 students in the United States (Open Doors, 2013). From this data it becomes clear that different groups of students will have quite distinctive experiences depending upon their place of destination. So research into student experiences must take account of the specific features of the place where they go to study. The experiences that students have, feeds into shifting patterns of application and recruitment with many foreign universities becoming known in China as "hot spots" for study because of their growing success and reputation.

Having established details of current trends I now wish to raise a number of issues related to the experiences of post-graduate students from China who go to study in OECD member states which have English as a first language, such as New Zealand, Australia, Canada, the USA and the UK. Substantial use is made of a range of statistics relating to flows of students from China towards a number of English speaking countries. The fieldwork employs the method of interview. The interviewees have been accessed through Chinese friends using a snowball method to Chinese overseas postgraduate students who study in different English speaking countries. The United States, UK, Australia and Canada are sites for the investigation because these are the preferred countries when Chinese students consider for their study overseas. There are three challenges of pursuing this particular type of research project. The first is about overcoming the problems about interviewees living and studying in different countries. This research uses "QQ" or "We Chat" to interview with them (Note 8). In addition, the research also pays attention on the data analysis in which the data analysis be analysed without being too distorted by the researcher's personal experience. The research also accounts for the way that varying social and cultural backgrounds affect how student participants relate their views on being included or excluded during their periods of study. 


\section{Three Key Elements of the Experiences of Chinese Students Studying Abroad}

This paper focuses upon three key elements of the experiences of Chinese students studying abroad: firstly, to consider the language barrier and its significance to student experiences; Secondly, the different attitudes and understanding about learning among Chinese students travelling abroad for post-graduate study; Thirdly, the pressure that arises from heavy course demands requiring completion within a short time spans. The present discussion therefore will move away from the fixed stages that Oberg used for his analysis and move into other relevant aspects. The three aspects cited above are just some from many others that could and should be studied when examining students studying abroad. I begin with the issue of the language barrier.

\subsection{The Language Barrier}

For Chinese students following postgraduate studies in English speaking countries, the first major challenge encountered comes from the language barrier. There are three models for academic writing in higher education: the study skills model, the academic socialisation model, and the academic literacy model (Lea \& Street, 1998). Zheng (2011) has shown how an emphasis upon study skills in relation to learning surface language, grammar, and spelling to students, can produce students who have achieved academic success in English studies but arrive with little ability to use their English interactively. From the outset Chinese students will have to undergo academic socialization involving them in a struggle to adapt their writing styles to fit into mainstream academic discourses and they will discover that each sub-discipline has evolved its own characteristic pattern of discourse into which they will need to be initiated.

The academic literacy model about how students cope with the demands of working in a different language is concerned about issues of the relationship between writing, identity, and power relations. Writing and reading in academic English is a great challenge especially as what they are learning in this mode does not necessarily help students with their everyday, common spoken English. So typically a newly arrived student is confronted with having to acquire a number of distinct types of English all at the same time as well as having to unlearn much of what they had been taught previously.

Therefore when applying for a place at a university students should know what to expect and find ways of avoiding becoming isolated because of problems with acquiring conversational English. When international students have had little experience of writing in English, expecting them to be able to suddenly acquire skills with academic writing presents a very big challenge (Dong, 1998; Rose \& McClafferty, 2001). Rose and McClafferty (2001) show how students may for example, display a series of errors in their use of English with many of the linguistic and rhetorical misconceptions reappearing in their writing. They also show that many students are unsure of various mechanical and grammatical rules even though they are literate in two or more languages.

Another issue for Chinese students is that the way they speak is structured by the thought processes and the linguistic patterns of their own first (and second) languages. They come to a place where the languages are not related to their own countries. On the basis of my own experiences as an overseas student in Britain, when I wrote academic assignments in English, my Chinese often interfered with my written expression. This also brings challenges to the work of the tutor of a Chinese student studying in a university in, for example, Toronto or Melbourne, because it is hard to make allowances between the understandable problems of a student struggling with an unfamiliar language and maintaining the rigorous standards of the subject (Ballard \& Clanchy, 1991). Therefore for students intending to study abroad it is suggested that a period of time is spent before travelling abroad trying to naturalise their spoken use of English. This will accelerate the "adjustment" and "recovery" periods and enable students to cope better with their need to acquire different forms of English both spoken and written.

\subsection{Different Attitudes and Understanding to Learning}

Other than the difference in language, the second challenge derives from different attitudes towards, and understandings of, learning. Li (2003) surveyed differences between Chinese and American students relating to their concepts of learning. In his survey, a list of the learning terms generated by American students featured "inquiry", "mental process", and "critical thinking", whereas for Chinese students learning related to ideas of "memorization" and "following teachers". Hard work can grind an iron rod into a needle. Li (2003) found that Chinese students felt that they should always have a book in their hand because knowledge for them comes from books. However, American students acknowledge learning as fulfilling their curiosity, interests and helping them to face challenges $(\mathrm{Li}, 2003)$. D. W. Chan and Chan (1999) found that across China teachers tended not support creative behaviours and personalities from their students instead, emphasizing learning procedures and concepts using the same kinds of activities. Cai (2005) discovered that many American teachers adopted different methods 
to encourage students to think on their own and for themselves. Things have remained much the same to the present time, although more recently greater numbers of Chinese students now know what to expect when they arrive in English speaking countries as their home universities in China have begun to prepare some of their students for the experiences of studying abroad.

Along with many other commentators Chang, L., Mak, M. C., Li, T., Wu, B. P., Chen, B. B., and Lu, H. J. (2011) have revealed how students from countries such as China, Japan and Korea rely on memorization in learning. In accordance with some aspects of traditionalist Chinese culture, learning implies acquiring the ability to memorize, to accept direction and follow precedent. To possess such knowledge is the path towards wisdom. This cultural preference arises in large part from the absolute need for the young to spend several years of hard work memorizing around 3,000 ideographic characters. In European cultures children are initially taught by a system to de-code words phonetically - a form of critical engagement with the written form (Fischer, 2005) while the learning process for Chinese requires intense repetition, copying and memorizing. Arising from the graphic qualities of Chinese there also arises an aesthetic and spiritual valuation of writing practices (calligraphy) which is largely absent from western phonetic teaching. Researchers such as Zhang and Dai (2004) have shown how Chinese students learn mathematics through memorization procedures such as young children being required to recite multiplication tables and complex trigonometric formulae whereas in some western countries the emphasis lies with using mathematics to solve problems or even for play. If this process is continued throughout the entire schooling period the young student become mentally conditioned to response reactions under direction so that when he or she enters a western university their ideas about learning are challenged by a different set of assumptions.

Ying Huang, one of the interviewees in this research about changing flows of students, followed a Masters level Degree in Comparative Education at a UK university. She revealed how she had to adapt to a different learning style in order to succeed. However, her first two months were difficult and she sometime felt uncomfortable when asked things like "Why" or "So what do you think about this?" from colleagues or lecturers.

The purpose of my studying there was to gain knowledge, you know what I mean about knowledge, but I did not think I obtained it. Usually, teachers only introduced limited basic information about specialized knowledge. For example, they only introduced the social background or main debates or the general development of the situation when we were learning about some educational theories. They would send a long reading list before the course and require group discussion each week within and out of the class. We had to explore why different scholars had these varying opinions on a theory through group discussions and many readings. For me it was really boring in the first two months because I did not know what I should say in the discussion and I did not form my own ideas even after the reading. Maybe I just did not become accustomed to this style. However, I gradually came to feel that it was a really effective learning method because I got to really know how to actively learn by myself and with fellow-colleagues as well as with the new surroundings.

This culturally fixed approach to knowledge transmission shapes not only students' attitudes towards study, but also teachers' pedagogical methods and national educational assessment systems. Consequently, when these students are evaluated by educational systems based on these countries' culture, challenges will appear because of the differences in attitudes to knowledge held by Chinese overseas students and their new academic lecturers. To these students, this difference in culture makes writing academic assignments harder because instead of reiterating and reproducing with accuracy the knowledge that has been delivered by their lecturer, they are now expected to present their own ideas and insights and will actually be marked down for performing as they would have done in China.

Things that are positively valued in China can be perceived to be negatives in another academic setting. For example, one overseas student who was from China who participated in the present research attended 19 courses during a single academic year within three terms. She would declare her course attendance as something she was proud of and would use this to demonstrate her commitment to study to her sponsoring university back in China when writing her annual report. However her tutors in the UK host university responded by saying that they regarded her course attendance as negative because she should have spent more time thinking rather than just accumulating knowledge from set courses. Lea and Street (1998) have pointed out that in different learning and cultural communities, what is perceived of as being appropriate for the writing practices of students has more to do with the way they understand what writing means and what is for, rather than with the way they perform in relation to surface features of language such as grammar. Critical engagement with language use lies at the heart of many western social sciences and humanities courses of study but is virtually absent in the Chinese context. Therefore the problem for students of adapting to their new university is much deeper than simply becoming 
more capable with using English. There is also a radically different conception of what language is and what it is for.

Zheng (2011) studied Chinese graduates in Canada, pointed out that the students in Social Sciences programmes displayed extensive concerns about how academic disciplines, and culturally-specific ways of thinking about ideas, were interfering with their academic writing. For these Chinese international graduates in Canada, to write critical articles was not just about using appropriate vocabulary and correct surface structures, but also coming to terms with ideas about critical thinking, which can differ in various academic disciplinary communities and national educational contexts. An example of this can be the very distinct discourse traditions between historians and philosophers. So for Chinese students studying abroad there will not be just one style of expression and discourse that they learn, because when they arrive they will encounter a range of different modes of critical thinking.

\subsection{The Pressure Comes from Heavy Course-Demands in a Short Period}

Chinese overseas students will experience the pressure from working intensively through a heavy course-load in a short period. Many universities in English speaking countries offer one-year postgraduate courses while equivalent standard postgraduate degrees usually take two to three years or longer in China. Hence, these Chinese students who have studied their postgraduate course in an English speaking country graduate will commence work earlier than their contemporaries who started similar postgraduate courses back home in China. In this ever-changing society, entering a workplace earlier with their foreign postgraduate degree means not only earning money but also gaining work experience earlier thus obtaining increased opportunities. In addition, their foreign degree confers improved the social status when back to China. There is a special title for such students-HaiGui (海归) overseas returners (Note 9). The economic and social capital benefit of securing such qualifications drives students to face the many challenges that been outlined above. Jackson (2010) points out that studying abroad provides significant benefits to students through their increased proficiency in the language of the host country and enhanced understanding of another culture. Therefore, these foreign postgraduate courses with their shorter duration attract many Chinese students despite the demands and challenges they pose. However, compared to the two or three year's postgraduate courses in China, the basic contents and requirement of the postgraduate programme in destination countries is almost the same.

The following two extracts concerning comparable standard degree for the MRes of Educational and Social Research come respectively from the Beijing Normal University (BNU) and the Institute of Education, University College London (IOE) which are respectively the top universities for studying education in China and the UK (Note 10).

The BNU: the programme requires students to study six core courses and write a dissertation of 20,000 words. The programme length is flexible from 2 to 3 years full-time. (Note 11)

The IOE: The programme consists of five courses and students will carry out a piece of research for a dissertation of 15,000 words. Students can complete the programme in one year of full-time study or two years' part-time study. (Note 12)

From this it is easy to see how similar programme courses and requirements for these two top universities are. These students have to finish the similar assignments but with a shorter time in their host countries. If these students cannot complete required courses in time, they may extend their study length but this extension will bring additional expenditure, including tuition fees and living expenses. This financial consideration inevitably brings more pressure upon them. Intending M.A. students following the one year course in English speaking universities should expect their experience to be very intensive indeed.

The comparable demands and expectations conceal more fundamental challenges for the visiting Chinese students - that of the qualitatively different expectations from the course itself. There are at least three aspects of the learning experiences that Chinese students must overcome. The first of these are the relationships between fellow-students, between teachers and students and between students and their courses. Fellow students are likely to be very international and multi-cultural bringing different perspectives, cultural assumptions and social backgrounds. Such students will often find it natural to initiate group discussions both in and out of the course and will not be socially reserved and deferential. The challenge for Chinese students is to adjust to this cultural diversity especially as group exchange and discussion will be one of the principal means within the course for learning. So if a student finds it difficult to become part of such discussion they risk cutting themselves off from one of the core processes of learning.

Another major change happens through teachers who act as supporters for their students' study and who perceive 
of their course content as a bridge to lead students to explore knowledge for themselves. Arising from this, teachers tend to perceive of themselves as study-partners of students rather than as initiators of knowledge. The more questions students ask and discuss means the more active is the thinking and interest among the students. Thus, students are welcomed to freely question course contents which teachers have devised and delivered. Therefore many Chinese students experience what amounts to a culture shock when they arrive at their new universities.

\section{Three Advantages of Chinese Oversees Students Have}

This section of the present paper shifts attention to three further issues of significance: mastering English, broadening vision and increasing self-confidence.

\subsection{Mastering English}

The use of English as a lingua franca worldwide for business, leisure, diplomatic, cultural and educational and other purposes appears to be continuing its growth (Firth, 1996; Knapp \& Meierkord, 2002; Tardy, 2004; Jenkins, 2007). Our world increasingly demands sophisticated awareness and skills about how the societies operate and also an ability to use English in a number of ways as a core aspect of global competency (Jackson, 2010). Postgraduates studying in English-speaking countries have to complete a range of courses, submit their dissertations and communicate with fellow students and academics using English. Invariably the English competency level of these postgraduates is much better than that of their colleagues who have completed their postgraduate degrees using the national language in their home countries. These international students increasingly need to function effectively in multi-national teams and they need to understand the cultural differences and historical experiences that can sometimes divide, as well as the common values and humanity that unite (Open Doors, 2013). This has come to be called inter-cultural competence. Moreover, through acquiring language itself, such students come to understand and be able to articulate different ideological perspectives which are linked to different cultures. Acquiring a language does not only broaden a person's linguistic skills; it also broadens a person's cultural sensitivity and awareness. This can be illustrated through a narrative concerning a Chinese student who lived with a British family while studying for her master degree at the London School of Economics. One evening her host-family organized a dinner for a family friend which was to take place around the time when the Chinese student would normally return to the house from the university. The host-mother invited the Chinese student to join them for dinner. While the student would have loved to participate in the dinner, she felt the host-mother was just being polite. So, as a polite response, the Chinese student said (Note 13) "It is lovely but I had dinner outside already, thank you very much". Fortunately, the host-mother was experienced and made a point of asking whether she was using a Chinese polite way or a British expressive way to answer this? The Chinese student smiled in recognition that this host-mother understood and exchanged a shared smile of recognition. In the end she participated in the dinner which she enjoyed and from which she learned much. Chinese cultural norms place a value upon humility and modesty and social responses tend to follow these rules. Chinese people tend to choose more implicit models to express the feelings, ideas and judgments. However, within the culture of a host-country such as the UK, people are likely to voice their opinions more directly and explicitly. As the Chinese student acquired greater facility with colloquial English she also acquired greater ease with expressing herself in a manner to which she had be unused to.

Johns and Swales (2002) explain how through learning a language such as English, one is also acquiring a route into different cultural norms and values. An overseas learning experience can help visiting students to overcome linguistically conditioned boundaries between people who come from different cultural backgrounds. Therefore, they will have more opportunities to communicate and integrate with the world in which they live- they will acquire a particular type of social capital. The lesson we learn from this is that study abroad does not simply enable the acquisition of greater formal skills such as learning another language; it also affects the way a student thinks and views the world and open doors to opportunities that can further develop personal and social capital.

\subsection{Study in English Speaking Countries: Broadening of Vision and Perspective}

Wenger (1999) has argued that learning involves active participation in a community of practice. This participation includes taking part in local events and activities with people in social groups. Different communities of practice form the complex social whole. Through these communities of practice, complex and inter-related social formations arise. It is through belonging to one or more of these "communities of practice" that people learn to relate more closely with each other (Lave \& Wenger, 1998). Post-graduates studying in other countries learn as they participate in local communities within their host institution and country. In other words, they are not just learning their subject knowledge, but also participating in social practices which take place within localised communities and thereby become absorbed as active members. When a student decides to leave 
China and take the unknown journey into another country they need to be brave and become involved in a variety of social settings that are not necessarily connected to their particular studies. Such involvement will lead to very important learning and widening of vision and perspective.

\subsection{Studying in Destination Countries Gives Students Increased Confidence}

The experiences of overcoming the challenge in foreign countries may give these students increased confidence. When these students study in foreign countries, they have to actively communicate in unfamiliar circumstance using their second or, in the case of most Chinese students, their third language. This process is often at first, full of isolation and loneliness, the "regression" stage spoken about earlier. As adjustment takes place the individual can become more tolerant and stronger. The fact that they have adapted becomes something they can feel proud of themselves for. These international students enhance their self-confidence and acquire a higher degree of independence and self-efficacy (Jackson, 2010). Something as everyday as finding suitable accommodation can at first seem impossibly challenging, but as they gradually succeed, they learn how to face self-doubt and establish a secure basis for their lives while studying abroad.

The tale of Junxiao (Note 14), a Chinese overseas student in Melbourne, Australia may illustrate the process under discussion. Junxiao seemed much younger than her chronological age but already she had a number of international experiences. In discussion about her experiences of adjustment as a foreign student she spoke of the time when her landlady asked her to leave the flat where she had been living. This was a shock because she had got on well with this landlady and also she had nowhere else to go. At first she had secured this accommodation through a Chinese agency so had no experience about how to find a room in an unfamiliar city by herself. Junxiao reported that she would cry and become emotional, not knowing what to do in such an emergency situation. However she found some room lettings information from the internet and asked for help from fellow-classmates. She then spoke to potential landlords using her Chinese English and discovered that several of these also spoke broken English being new residents themselves. Junxiao cited this story as an example of how only two weeks later, when she moved and had all her belongs in the new room and was comfortably sitting in front of desk, she felt she was stronger for having had this experience. This instance may alert those readers who are potential students wishing to study abroad, to be prepared to face uncertainty and instead of calling up parents in China and crying for an hour over the phone, take practical steps to deal with the situation and use the challenge as an opportunity to learn. The other element to this tale is the way that Junxiao shared her fears and worries with colleagues only to discover that some of them had experienced exactly the same thing as she was going through.

For many female students, another aspect of this issue of developing self confidence is for them to learn not to rely upon fantasized projections concerning a mythical "Mr. Right" arriving on the scene one sunny day during their overseas study. This imaginary, archetypal, Mr. Right is typically strong, independent, brave and patient because many female students think they lack such characteristics in their personality. There is a likelihood that they may not meet this man until after they graduate, so it may be wise for time abroad to be used to become stronger, more independent, braver and more patient while studying. International students are enriched by classrooms, campuses and communities in ways that endure long after they return to their home countries. Therefore, the connections made during international education experiences can last a lifetime (Ryan in Open Doors 2013, 2013).

\section{Suggestions for Students Who Want to Study in Overseas Countries}

The experience of studying overseas can be one of the most exciting, rewarding, and challenging adventures of a lifetime. Before deciding upon a destination student will have to consider the financial realities this will entail. The websites of embassies of many countries publicise the living expenses, something one may also find offered through many universities. This is important because things like transport, food and accommodation costs are much higher elsewhere than in China. One very worthwhile activity for overseas students is to secure paid employment while also studying but opportunities for this vary according to which country one is studying in.

Students quickly discover that passing the language entrance examination of the university is never sufficient for studying overseas. In fact the process of studying the formal aspects of English in order to pass the test can inhibit the process of acquiring colloquial competence and understanding. Students will realise that the passing of their IELTS or TOFL tests will be at best, only the beginning of a process of acquiring fluency in English and will not be the end. Few Chinese students spend time before leaving home, consciously listening to and reading a variety of English language programmes and articles, in the dialects of the countries they are intending to go to. The variants between standard British, American and Australian Englishes (Kachru, 1997) are quite striking. These variations also exist within countries like the USA and UK where for example, strong degrees of dialect 
variation exist in different parts of the country.

\section{Conclusion}

Chinese students following postgraduate studies in their host countries often encounter many challenges because the systems of education and assessment are different than in China. In these countries, Chinese post-graduates not only study a different language and a special subject in one field, but also study a different culture and encounter varied ways of seeing and thinking through participating in all kinds of activities in their local communities. These studies require students to jump away from many of their established perspectives and ways of seeing and thinking based on Chinese cultural norms and enter into a social system where different values exist. They find themselves in new surroundings which may pose specific challenges such as someone from southern China experiencing for the first time three months of cold and snow during a winter. They can find themselves in new cultural settings which present challenges such as mixed gender residencies whereas before there were separate blocks for male and female students. For many students making this jump into the unknown is a positive experience and facing such challenges facing is exciting at a personal level.

Accelerating globalization has led to increased investment in knowledge industries to meet the demand for highly educated individuals who can interrelate effectively with people from different cultures and succeed in a competitive world (Turner \& Robson, 2008). Estimates from United Nations Educational, Scientific and Cultural Organization (UNESCO) over a decade ago, that the number of Chinese students who would go to foreign countries to pursue postgraduate degrees would rise to almost 8 million by 2025 appears from the perspective of 2014 to be coming true (cited from Davis, 2003). However, extrapolating from current Chinese figures it may be possible from the perspective of 2014 to imagine an even larger number. If, as Fantini has argued (2006) international postgraduates overcome the culture shocks of new environments and, adapt socially, linguistically, academically, culturally, personally and economically, they develop sophisticated awareness of self and others and become the owners of enhanced social and cultural capital. The young students who lie behind the statistics will become generation driving the globalized cultural and economic expansion of the coming century. If present growth patterns continue many millions of such people will be Chinese and this can only be something positive for the future of our country and its prosperity. The student experience which Oberg described so effectively during the late 1950s has in many aspects changed so a more nuanced account is necessary which resists simplified categorisations.

\section{Acknowledgements}

This study is an achievement of the youth project of '12th five-year plan' of Chinese national social science fund in 2014. The number of project is CIA140189. The invaluable help and advice by Dr. Steven Cowan is gratefully acknowledged.

\section{References}

Ballard, B., \& Clanchy, J. (1991). Assessment by misconception: Cultural influences and intellectual traditions. Assessing second language writing in academic contexts, 19-35.

Cai, J. (2005). US and Chinese teachers' constructing, knowing, and evaluating representations to teach mathematics. Mathematical Thinking and Learning, 7(2), 135-169. http://dx.doi.org/10.1207/ s15327833mt10702_3

Chan, D. W., \& Chan, L. K. (1999). Implicit theories of creativity: Teachers' perception of student characteristics in Hong Kong. Creativity Research Journal, 12(3), 185-195. http://dx.doi.org/10.1207/s15326934crj1203_3

Chang, L., Mak, M. C., Li, T., Wu, B. P., Chen, B. B., \& Lu, H. J. (2011). Cultural adaptations to environmental variability: An evolutionary account of East-West differences. Educational Psychology Review, 23(1), 99-129. http://dx.doi.org/10.1007/s10648-010-9149-0

Cheng, X., \& Miao, D. G. (2010). Reviews on the Sixty Year History of Chinese Study in Abroad (1949- 2009). Southeast Asian Studies, 1, 79-87.

China Education Online. (2013). The Trend Report of Students Who Study in Abroad in 2013. Retrieved May 22, 2014, from http://www.eol.cn/html/lx/baogao2013/page1.shtml

Chinese Central TV. (2013). Studying Abroad: A Prevailing Trend for Chinese Students. Retrieved May 16, 2014, from http://english.cntv.cn/program/cultureexpress/20131108/101852.shtml

Davis, T. M. (2003). Atlas of Student Mobility. New York: Institute of International Education. 
Dong, Y. (1996). Learning how to use citations for knowledge transformation: Non-native doctoral students dissertation writing in science. Research in the Teaching of English, 30(4), 428-457.

Fantini, A., \& Tirmizi, A. (2006). Exploring and Assessing Intercultural Competence. World Learning Publications. Paper 1. Retrieved May 16, 2014, from http://digitalcollections.sit.edu/worldlearning publications $/ 1$

Firth, A. (1996). The Discursive Accomplishment of Normality: On lingua franca English and Conversation Analysis. Journal of Pragmatics, 26(2), 237-259. http://dx.doi.org/10.1016/0378-2166(96)00014-8

Fischer, S. R. (2005). History of Writing. London: Reaktion Books.

Jackson, J. (2010). Intercultural Journeys: From Study to Residence Abroad. London: Palgrave MacMillan. http://dx.doi.org/10.1057/9780230277083

Jenkins, J. (2007). English as a Lingua Franca: Attitude and Identity. Oxford: Oxford University Press.

Johns, A. M., \& Swales, J. M. (2002). Literacy and Disciplinary Practices: Opening and Closing Perspectives. Journal of English for Academic Purposes, 1(1), 13-28. http://dx.doi.org/10.1016/S1475-1585(02)00003-6

Kachru, B. B. (1997). World Englishes and English-using communities. Annual Review of Applied Linguistics, 17, 66-87. http://dx.doi.org/10.1017/S0267190500003287

Knapp, K., \& Meierkord, C. (2002). Lingua franca communication. Frankfurt: Peter Lang.

Lave, J., \& Wenger, E. (1991). Situated Learning: Legitimate peripheral participation. Cambridge: Cambridge University Press. http://dx.doi.org/10.1017/CBO9780511815355

Lave. J., \& Wenger, E. (1998). Communities of practice: Learning, meaning, and identity. Cambridge: Cambridge University Press.

Lea, M. R., \& Street, B. V. (1998). Student writing in higher education: An academic literacies approach. Studies in Higher Education, 23(2), 157-172. http://dx.doi.org/10.1080/03075079812331380364

Li, J. (2003). U.S. and Chinese cultural beliefs about learning. Journal of Educational Psychology, 95(2), 258-267. http://dx.doi.org/10.1037/0022-0663.95.2.258

Li, L., \& Dong, S. H. (2008). Attention to the Officials Who Come Back from Overseas Returnees. Southern Weekly.

Oberg, K. (2006). Cultural shock: Adjustment to new cultural environments. Curare, 29(2), 3.

OECD. (2013). How many students study abroad and where do they go? Education at a Glance 2013: Highlights. Retrieved May 12, 2014, from http://www.oecd-ilibrary.org/docserver/download/9613041ec012.pdf? expires $=1427542440 \& \mathrm{id}=\mathrm{id} \&$ accname $=$ guest $\&$ checksum $=0280 \mathrm{D} 4 \mathrm{~B} 5440030 \mathrm{E} 037268 \mathrm{DD} 1 \mathrm{D} 99 \mathrm{ECA} 35$

Open Doors 2013. (2013). International Students in the United States \& Study Abroad by American Students are at All-Time High. Retrieved May 12, 2014, from http://xm.xuelema.com/Info/7675.html

Rose, M., \& McClafferty, K. A. (2001). A call for the teaching of writing in graduate education. Educational Researcher, 30(2), 27-33. http://dx.doi.org/10.3102/0013189X030002027

Tardy, C. M. (2004). The role of English in scientific communication: Lingua franca or Tyrannosaurus rex? Journal of English for Academic Purposes, 3(3), 247-269. http://dx.doi.org/10.1016/j.jeap.2003.10.001

Turner, Y., \& Robson, S. (2008). Internationalizing the university. London: Continuum International. Publishing Group.

Wang, H. Y., \& Li, N. (2008, March 27). 30 years of state-financed study abroad. People's Daily (Overseas Edition).

Yao, L. (2004). The Chinese overseas students: An overview of the flows change. Paper presented at the Australian Population Association 12th Biennial Conference on Population and Society: Issues, Research, and Policy, Canberra, Australia.

Zhang, D., \& Dai, Z. (2004). The "two basics" mathematics teaching approach and the open ended problem solving in China. Research in Mathematical Education, 8(3), 123-144.

Zhang, Z. (2011). A Nested Model of Academic Writing Approaches: Chinese International Graduate Students' Views of English Academic Writing. Language and Literacy, 13(1), 39-59. 


\section{Notes}

Note 1. Republished in Curare, 2006, 29(2), 3.

Note 2. China Education Online: The trend report of students who study in abroad in 2013, http://www.eol.cn/ html/lx/ baogao2013/page1.shtml. Graph adapted by the author.

Note 3. Source: Imperial College Student Union.

Note 4. The National Art Museum in the 20th Century, Moscow.

Note 5. China Education Online: The trend report of students who study in abroad in 2013, http://www.eol.cn/ html/lx/ baogao2013/page1.shtml. Graph adapted by the author.

Note 6. Such sayings are very commonplace within Chinese culture and variations of these words can be found in many places.

Note 7. OECD: Education at a Glance, 2013, http://dx.doi.org/10.1787/888932847583. Graph adapted by the author.

Note 8. "QQ" or "We Chat" is two popular Chinese chat platforms for Chinese online exchanges.

Note 9. The pronunciation of HaiGui is the same as with Sea Turtle 海龟 in Mandarin. HaiGui can also mean people with advanced ideas about management and skills as well as multi-cultured and richly experienced.

Note 10. In 2014 the IOE in London was assessed in quality ranking standards for Education Studies as number 1 in the world.

Note 11. The original version of this extract is in Chinese on the website of the BNU, from which I have translated http://graduate.bnu.edu.cn/ReadNews.aspx?NewsId=111010125059.

Note 12. http://www.ioe.ac.uk/study/RMR9_EDU999.html.

Note 13. The dialogue was reported to the author by as part of another piece of research.

Note 14. Junxiao left a secure position in a university in order to follow her dream of studying abroad.

\section{Copyrights}

Copyright for this article is retained by the author(s), with first publication rights granted to the journal.

This is an open-access article distributed under the terms and conditions of the Creative Commons Attribution license (http://creativecommons.org/licenses/by/3.0/). 